\title{
PEGADA ECOLÓGICA DO LIXO: DESENVOLVIMENTO E APLICAÇÃO DE UMA SEQUÊNCIA DIDÁTICA PARA A EDUCAÇÃO AMBIENTAL
}

\author{
Ronualdo Marques ${ }^{1}$; Claudia Regina Xavier²
}

\section{RESUMO}

A Educação Ambiental (EA) é uma temática que interfere diretamente em nossas vidas e discuti-la favorece a compreensão da realidade e a participação social. Este estudo tem o objetivo analisar a aplicação do Recurso Educacional "Pegada Ecológica do Lixo" desenvolvido para a Alfabetização Científica e estimular a divulgação de práticas no que se refere à EA. Observou-se na aplicação da Sequência Didática uma interação e inter-relação de aprendizagem para fomentar o debate acerca da problemática ambiental. Pôde-se concluir que a Educação Ambiental no currículo escolar de forma contextualizada estimula o rompimento com práticas isoladas, pontuais e com a educação mecanicista e conservadora, visto que o desenvolvimento de ações integradas e participativas potencializa as discussões que emergem das relações entre os seres humanos, a sociedade e a natureza.

Palavras-chave: Pegada Ecológica do Lixo; Alfabetização Científica; Sequência Didática.

\section{ECOLOGICAL FOOTPRINT OF GARBAGE: DEVELOPMENT AND APPLICATION OF A DIDACTIC SEQUENCE FOR ENVIRONMENTAL EDUCATION}

\begin{abstract}
Environmental Education (EA) is a theme that interferes directly in our lives and discussing it favors understanding of reality and social participation. This study aims to analyze the application of the Educational Resource "Garbage Ecological Footprint" developed for Scientific Literacy and stimulate the dissemination of practices with regard to EA. It was observed in the application of the Didactic Sequence an interaction and inter-relation of learning to foment the debate about the environmental problematic. It could be concluded that the Environmental Education in the school curriculum in a contextualized way stimulates the break with isolated practices, punctual and with the mechanistic and conservative education, since the development of integrated and participative actions potentiates the discussions that emerge from the relations between human beings, society and nature.
\end{abstract}

1 Mestre. Universidade Tecnológica Federal do Paraná. E-mail: ronualdo.marques@gmail.com. 2 Doutora. Universidade Tecnológica Federal do Paraná. E-mail: cxavier.utfpr@gmail.com. 
Keywords: Ecological Garbage Footprint; Scientific Literacy; Following teaching.

\section{Introdução}

A Educação Ambiental (EA) é uma temática que interfere diretamente em nossas vidas e discuti-la favorece a compreensão da realidade e a participação social. A EA é regida pela Lei no 9.795/99, Política Nacional de Educação Ambiental (BRASIL, 1999). Os temas ambientais constituem questões sociais relevantes para as discussões em classe destacando os inúmeros problemas urgentes; todavia é comum que os discentes em quaisquer níveis educacionais apresentem dificuldades para a aprendizagem e as discussões sobre a EA, dada à complexidade das questões socioambientais.

Trabalhar a Educação Ambiental nas escolas é uma tarefa árdua, uma vez que envolve uma série de variáveis como a concepção do professor, o contexto em que a escola está inserida, a problematização que pode surgir a partir desta e os recursos didáticos disponíveis que servirão de referência aos alunos.

Nesse cenário a proposta de Educação Ambiental se destaca como possibilidade de construção desse novo pensar, por tratar-se, de uma proposta educativa que se destina à formação de valores e atitudes necessários a uma nova postura frente às questões ambientais, por meio de um processo educativo emancipatório.

Neste trabalho e no REA optou-se pela nomenclatura do lixo ou resíduo sólido, pois esta é mais próxima da realidade do estudante e pode ser mais propícia para sua sensibilização ambiental. O lixo sempre foi um problema no meio ambiente e um tema bastante discutido tanto no meio acadêmico como na sociedade. O aspecto ambiental do lixo é de importância indiscutível. Entretanto, pouco se fala ainda das suas implicações sociais e outra vertente também pouco discutida é sua relação com a cultura. No que diz respeito a suas implicações sociais, a problemática do lixo relaciona-se à forma como cada parcela da sociedade pode lidar com o tema, sendo pela forma de lançar o lixo no ambiente ou pela forma de minimizar os impactos causados pela deposição errada do lixo, oferecendo novas alternativas sobre o que fazer com 
ele.

Sendo assim, o presente trabalho apresenta o desenvolvimento e análise da aplicação de um Recurso Educacional Aberto (REA) "Pegada Ecológica do Lixo" aplicado numa Sequência Didática a partir da temática do lixo no Ensino de Ciências possibilitando trabalhar a Educação Ambiental de forma contextualizada aliando teoria á prática, fomentando discussões sobre a produção, geração e impactos ambientais do lixo no meio ambiente.

O ambiente escolar não é diferente dos demais espaços urbanos, suas atividades resultam também na produção de resíduos sólidos. A abordagem da temática ambiental no espaço escolar não deve ser adotada apenas pela exigência da legislação, ou mesmo o modismo do termo sustentabilidade na mídia, mas, sobretudo, deve estar pautada na verdadeira Educação Ambiental que visa refletir a realidade e promover mudanças, que transformam meros receptores de conhecimento em cidadãos críticos capazes de refletir sobre sua realidade (MARQUES et al., 2017).

Nesse sentindo, pensou-se na conexão a temática do lixo associado ao conteúdo de Ciências do $6^{\circ}$ ano do Ensino Fundamental previsto nos livros didáticos e no Planejamento da Disciplina de Ciências, tornando viável a desenvolvimento de um Recurso Educacional Aberto (REA) organizado para aplicação em uma Sequência Didática (SD) que investigue e trabalhe questões relacionadas ao Lixo, de forma que o processo de aprendizagem se dê mediado pela teoria e a prática possibilitando a sensibilização e reflexões que permeiem mudanças culturais a fim de sensibilizar quanto ao problema do Lixo.

Assim o objetivo da SD é apresentar aos professores uma metodologia de trabalho envolvendo a temática do lixo por meio de aulas dinâmicas com diversos tipos de instrumentos didáticos para que a aprendizagem ocorra de forma significativa. Desta forma, o professor poderá abordar os conceitos em torno de um tema gerador de conhecimento destacado como LIXO, de maneira contextualizada próxima a realidade dos alunos, possibilitando uma sensibilização e mudança cultural para a prevenção e compreensão dos impactos ambientais decorridos do descarte inadequado destes resíduos.

Marques e Xavier (2018) evidencia que o desenvolvimento da temática Educação Ambiental no Ensino de Ciências contribui para a construção do conhecimento científico de forma contextualizada, utilizando ferramentas que 
permitam aos alunos exercitarem a capacidade de pensar, refletir e tomar decisões, iniciando assim um papel de amadurecimento, tendo em vista as inúmeras inter-relações que o ser humano mantém com o ambiente e viceversa e as demandas que isso gera para a sua formação como cidadão. Delizoicov et al., (2011) reafirma que a escola é um espaço onde as pessoas aprendem o tempo todo, construída e reconstruída a cada dia, no qual todos têm o que aprender e ensinar, aprendem a relacionar-se e a conviverem com os seus próprios valores e sentimentos.

No capítulo 1, iniciamos a ordenação racional desta pesquisa tendo no capítulo introdutório a apresentação da problemática, justificativa, objetivo e fundamentação teórica partindo do pressuposto da importância da Educação Ambiental no Ensino de Ciências com o desenvolvimento e aplicação de uma Sequência Didática sobre a Pegada Ecológica do Lixo. No capítulo 2 inicia-se com aspectos metodológicos sobre o desenvolvimento do Recurso Educacional intitulado: Pegada Ecológica do Lixo e aplicação deste numa Sequência Didática. No capítulo 3, apresento a discussão e resultados com as ilustrações do Recurso Educacional Aberto e Aplicação numa Sequência Didática. Por último se apresentam as considerações finais da pesquisa na seção 6 , seguida das referências empregadas neste estudo.

\section{Recurso Educacional Aberto}

Uma das tendências que emergem com o surgimento da internet e o uso das mídias na Educação é norteada pela colaboração e interatividade da cultura digital; a proposta deste movimento é a de que todos devem ter a liberdade de usar, personalizar, melhorar e redistribuir ferramentas educativas, sem restrições, ampliando assim o conhecimento. Para isso, é necessária a utilização de Recursos Educacionais Abertos (REA).

O termo REA foi definido em 2002 em Paris, no Fórum da Organização das Nações Unidas para Educação, Ciência e Cultura (UNESCO), onde discutiam o impacto de recursos abertos na democratização do ensino em todo mundo. A definição mais usual dos Recursos Educacionais Abertos é: 
adaptados por terceiros. $\mathrm{O}$ uso de formatos técnicos abertos facilita $\mathrm{o}$ acesso e o reuso potencial dos recursos publicados digitalmente. Recursos educacionais abertos podem incluir cursos completos, partes de cursos, módulos, livros didáticos, artigos de pesquisa, vídeos, testes, software, e qualquer outra ferramenta, material ou técnica que possa apoiar o acesso ao conhecimento (UNESCO, 2011).

Alguns dos objetivos dos REA quanto à sua utilização para a Educação acessível para todos, é "levar à equidade de acesso e a liberdade de aprendizado para todos fazendo uso de Recursos Abertos e encorajando práticas educativas" (AMIEL, 2012, p. 29); "valorizar práticas de aprendizagem mais próximas à cultura da web e da sociedade do conhecimento" (ROSSINI e GONZALEZ, 2012); "resgatar o papel dos professores enquanto protagonistas privilegiados dos processos educativos" (PRETTO, 2012); "buscar a interdisciplinaridade através de projetos estruturados com o uso do REA" (STAROBINAS, 2012).

O REA dá oportunidade de "expor um pouco de nós, de nossas opiniões, das ideias de nossos estudantes, para engrandecer nossos materiais e compartilhar nossos traços e identidade organizacional com qualquer outra pessoa que queira neles se inspirar" (STAROBINAS, 2012).

Os REA vêm ao encontro das expectativas de melhoria da Educação, sendo um modo de quebrar as barreiras do conhecimento pago, o que limita os acessos de quem o procura. Estes recursos podem ser vistos como uma forma igualitária de acesso ao conhecimento.

Pretto (2012) aponta que os REA proporcionam a autonomia, construção e criação de autores que estão empenhados numa modificação da estrutura de disponibilidades de recursos de ensino, no qual se deve "pensar nos REA como possibilidade emancipatória do indivíduo, nação ou cultura". Para o autor, a adoção de REA pode ser o início necessário para esta mudança em direção à Educação de qualidade.

Nesta perspectiva, destacamos as Sequências Didáticas (SD) na aplicação do REA como uma estratégia que oportuniza a aprendizagem aos indivíduos de forma ampla e sistematizada. Zabala (1998, p. 18) define as SD como "um conjunto de atividades ordenadas, estruturadas e articuladas para a realização de certos objetivos educacionais que têm um princípio e um fim, conhecidos tanto pelos professores como pelos alunos", constituindo-se como 
uma ponte entre o conhecimento científico e o estudante. $O$ trabalho com SD pode proporcionar a construção dos conhecimentos numa progressão de atividades em etapas encadeadas, contextualizadas e significativas, promovendo a consolidação dos conceitos e tornando mais eficiente o processo educativo.

\section{Metodologia}

Essa pesquisa foi aplicada na perspectiva da Pesquisa Participante que segundo Brandão (2006) compreende um processo compartilhado de desconstrução, construção e reconstrução de conhecimentos em uma ação transformadora e emancipadora.

Por ser crítica-dialética, a Pesquisa Participante busca envolver aquele que pesquisa e aquele que é pesquisado no estudo do problema a ser superado, conhecendo sua causa e construindo coletivamente as possíveis soluções. Para a Pesquisa Participante, os saberes dos indivíduos construídos no cotidiano da vida comunitária são partes importantes no processo de construção do conhecimento (BRANDÃO, 2006).

A pesquisa foi realizada no Colégio Estadual Júlia Wanderlei no

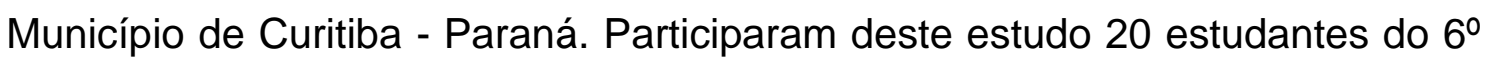
ano do Ensino Fundamental, respeitando a privacidade e o sigilo do educando conforme termo de aprovação do Comitê de Ética nº 60796516.0000.5547.

\section{Desenvolvimento do Recurso Educacional Aberto}

A pesquisa proporcionou a criação de um Recurso Educacional Aberto que trata de uma Sequência Didática "Pegada Ecológica do Lixo" para uso em aulas referentes à temática do lixo. Este material foi desenvolvido com ampla pesquisa em livros, artigos, documentos oficiais (Leis, DCN, PCN, PNEA), sites, vídeos, entre outros que utilizam a temática do lixo. O objetivo da elaboração do REA foi criar um material para auxiliar professores de Ciências ou outras disciplinas por se tratar de um conteúdo transversal dentro do ensino, cabendo aos professores adaptá-lo à sua realidade. O Recurso Educacional Aberto foi pensando para ser um material dinâmico contendo atividades, músicas, vídeos, dinâmicas, além de comentários e dicas ao professor. 
Este Recurso Educacional Aberto é fundamentado nos objetivos do Programa de Pós-Graduação em Formação Científica, Educacional e Tecnológica (PPGFCET), para "formar disseminadores de conhecimento nos campos pedagógico e tecnológico, dentro do sistema educativo nacional" (PPGFCET, 2017). A ideia é que o conhecimento produzido na pesquisa possa ser disseminado amplamente a professores do Ensino Básico.

Este produto educacional está disponível no Repositório Institucional da Universidade Tecnológica Federal do Paraná, do PPGFCET-UTFPR e na Base RIUT da UTFPR, em domínio público para utilização e adaptação para a sua utilização conforme necessidade.

\section{Aplicação do Recurso educacional numa Sequência Didática}

A Sequência Didática está organizada numa sequência de aulas que se constituiu em um total de 11 encontros com 2 aulas de 50 minutos cada. Elas foram desenvolvidas nas aulas da disciplina de Ciências, em uma turma do $6^{\circ}$ ano do Ensino Fundamental.

A SD é flexível e possui elementos, tais como: objetivo, justificativa, conteúdo, ano de escolaridade, tempo estimado para aula, número de aulas necessárias, material necessário, critérios de avaliação e instrumentos de avaliação. A SD perpassa por inúmeras etapas, na qual é preciso instigar a discussão coletiva, exibições de vídeos, músicas, aulas expositivas, pesquisa bibliográfica, aulas experimentais e outros que surgirem de acordo com a necessidade das aulas.

O desenvolvimento da Sequência Didática de aulas de forma mais detalhada se encontra no Recurso Educacional Aberto "Pegada Ecológica do lixo".

\section{Resultados e Discussão}

Neste momento são apresentados e discutidos a análise da aplicação do Recurso Educacional Aberto "Pegada Ecológica do Lixo" numa Sequência Didática, que se organiza pela interpretação dialógica dos documentos de cada uma das etapas desenvolvidas de acordo com os objetivos e Metodologia deste trabalho. 


\section{Desenvolvimento do Recurso Educacional Aberto: Pegada Ecológica do Lixo.}

O Recurso Educacional Aberto "Pegada Ecológica do Lixo" é uma Sequência Didática constituída por 48 páginas, incluindo capa e contracapa, diagramada para impressão colorida em formato de Revista $(20 \times 26,5 \mathrm{~cm})$.

A Figura 1 apresenta a capa do Recurso Educacional Aberto que está disponível no repositório do Programa de Pós-Graduação em Formação Científica, Educacional e Tecnológica.

Figura 1 - Capa do Recurso Educacional Aberto "Pegada Ecológica do Lixo"

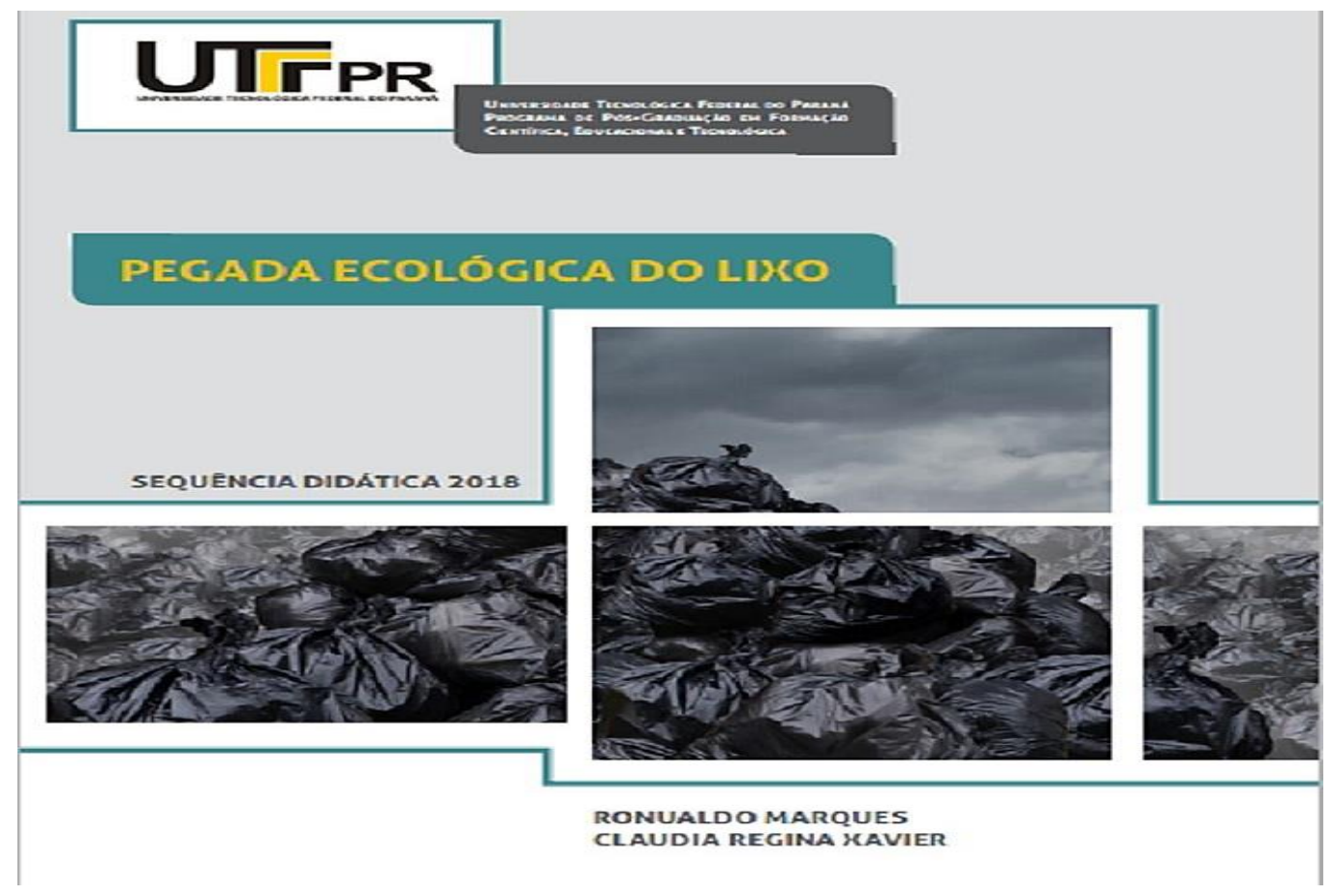

Fonte: Autores

Além do arquivo diagramado para pequenas tiragens, também está disponibilizado um arquivo para gráfica offset - de grande tiragem - e outro para impressões caseiras - ideal para visualização no computador, possibilitando a impressão do texto em folhas em frente e verso, ou só frente, indicada caso o professor queira fazer uma apostila ou grampear próximo da parte superior esquerda das folhas, podendo imprimir duas páginas A4 por folha A4. 
O objetivo do Recurso Educacional Aberto é ser um material prático e motivador para o professor, planejado com a intenção de ser uma leitura compreensível capaz de auxiliá-los em atividades e práticas trabalhando a temática ambiental da pegada ecológica do lixo.

Deste modo, utilizou-se uma metodologia em formato de Sequência Didática para a sistematização do conhecimento e aspectos relevantes que contemplem as discussões relevantes à Educação Ambiental, como mostra a Figura 2.

Figura 2 - Esquema para uso do recurso como apresentado no REA

\section{Metodologia}

Fluxograma 1: Representação da Metodologia

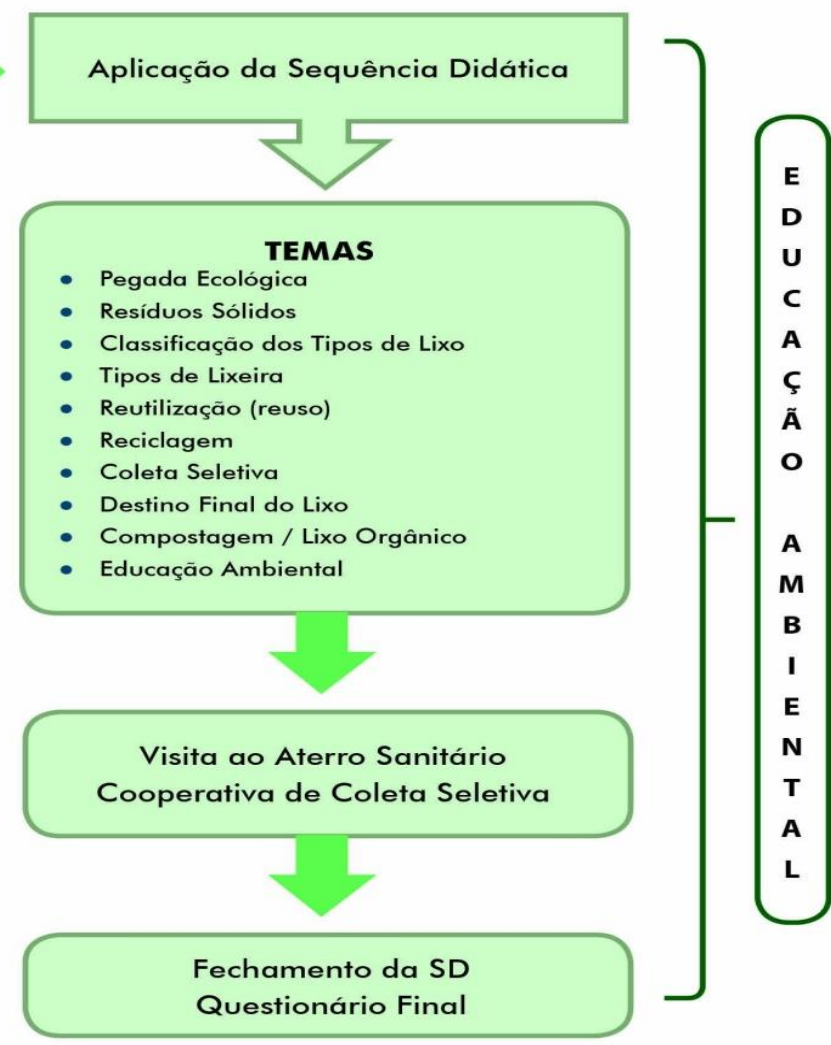

Fonte: Autores

\section{Análise da Aplicação do Recurso Educacional Aberto "Pegada Ecológica do Lixo"}

Para finalizar e avaliar a eficácia de aplicação da Sequência Didática do Recurso Educacional Aberto Pegada Ecológica do Lixo, foram realizadas rodas de conversa para verificar os conceitos aprendidos, construção da linguagem 
cientifica, confrontando diferentes opiniões e novos posicionamentos, a partir das aulas teóricas e práticas estimulando-os, assim, à criatividade e ao "saber ouvir", dando oportunidade aos colegas de se expressarem suas opiniões, dúvidas e anseios. A roda de conversa, como instrumento de trabalho, não foi escolhida sem antes nos depararmos com a necessidade de propiciar à nossa pesquisa um caráter de cientificidade, o que implica caracterizá-la como de natureza qualitativa e determinar sua posição como abordagem legítima da busca do conhecimento científico, posto que esse tipo de pesquisa "[...] é um meio para explorar e para entender o significado que os indivíduos ou os grupos atribuem a um problema social ou humano" (CRESWELL, 2010, p. 26).

É perceptível por meios destes resultados que os alunos desconhecem vários conceitos científicos ao que se referem à temática do lixo, sendo assim, uma importante temática para ser utilizada como instrumento para aprofundamento teórico e práticas que instigue a curiosidade do aluno despertando o interesse para o Ensino de Ciências e a Educação Ambiental.

A partir da explanação teórica em relação aos resíduos sólidos, foram realizadas associações com o cotidiano observado pelos alunos além de vídeos, imagens e propagandas preventivas retiradas da internet, onde os mesmos identificaram ações que levam a uma correta ou inadequada disposição de resíduos sólidos urbanos no meio ambiente. Foram citados ainda exemplos de odores fétidos e contaminação de recursos hídricos onde são despejados lixos, além dos animais e vetores de doenças que são atraídos pelos resíduos orgânicos em decomposição (SANTOS; FEHR, 2007).

A compreensão desses conceitos e práticas correspondentes é fundamental para a formação em uma sociedade que almeje diminuir os impactos ao ambiente. Os resultados obtidos nas discussões estão de acordo com a ideia de Souza (2007), que afirma que na aula prática o aluno pode motivar-se mais, visualizar o uso pragmático daquele conteúdo em sua vida cotidiana, facilitando dessa forma a aprendizagem significativa, pleonasmo intencional.

Ao se trabalhar a Compostagem na aula prática, foi percebido que a implantação de uma composteira e a realização da técnica na escola ou em suas residências é muito importante porque a partir dela é possível despertar a atenção dos alunos para alguns aspectos, tais como, o desperdício de 
alimentos e a importância de se adotar alternativas criativas e viáveis, que amenizem os impactos ambientais negativos.

Envolver os alunos neste processo possibilita a difusão do pensamento reflexivo e crítico frente ao cenário ambiental atual, estimulando-os a uma participação ativa com disseminação de um conhecimento sobre a questão ambiental, que faz parte do cotidiano de cada um. A Educação Ambiental exige assim novas orientações e práticas pedagógicas onde se plasmem as relações de produção de conhecimentos e os processos de circulação, transmissão e disseminação do saber ambiental. Isto coloca a necessidade de incorporar os valores ambientais e novos paradigmas do conhecimento na formação dos novos atores da educação ambiental e do desenvolvimento sustentável (LEFF, 2005, p. 251).

A visita ao Aterro Sanitário de Curitiba permitiu diversas reflexões para somar aos conhecimentos obtidos na Sequência Didática onde os alunos puderam compreender na prática o lixo comum todo, geração de lixo diário, o tratamento de chorume, vida útil do aterro, processo de decomposição, falta de sensibilização e conscientização referente á separação do lixo e reciclagem. As observações dos alunos ao se conhecer aspectos do ambiente, compreendeuse que o uso de aterros sanitários também não é ambientalmente satisfatório. Mesmo que se proteja o solo para impedir a infiltração de líquidos poluentes, o tratamento do chorume e a instalação dos dutos para a captação de gases produzidos, que o lixo seja compactado, ainda assim não será uma solução definitiva, pois por quanto tempo a Terra suportará servir de tapete encobrindo as nossas "sujeiras"? (MARQUES et al., 2017).

A Educação Ambiental é evidenciada como a melhor alternativa para instigar a consciência crítica na população em geral, a partir da análise dos problemas por ela vivenciados, e determinar sua participação na solução destes problemas (SILVA, 2005). A maneira de perceber o ambiente determina o grau de preservação que os indivíduos estão dispostos a exercer sobre o meio (SOUTO et al., 2009), e no presente estudo acredita-se ter-se despertado nos alunos uma visão do meio ambiente.

O diálogo no desenvolvimento da Sequência Didática favorece o espaço de formação, de troca de experiências, de confraternização, de desabafo, muda caminhos, forja opiniões, razão por que a roda de conversa surge como 
uma forma de reviver o prazer da troca e de produzir dados ricos em conteúdo e significado para a pesquisa na área de educação bem como nas correlações sobre os Resíduos Sólidos. No contexto da Roda de Conversa, o diálogo foi um momento singular de partilha, uma vez que pressupõe um exercício de escuta e fala.

As colocações de cada participante foram construídas a partir da interação com o outro, sejam para complementar, discordar, sejam para concordar com a fala imediatamente anterior. Conversar, nesta acepção, remete à compreensão de mais profundidade, de mais reflexão, assim como de ponderação, no sentido de melhor percepção, de franco compartilhamento. Fica notável quando um elemento não aparece no discurso do aluno, os colegas complementam permitindo que o aprendizado não seja apenas linear, mas um ensino dinâmico e interativo na formação integral do aluno (Zabala, 1998, p. 199). É preciso muitas vezes romper as barreiras entre o professor e o aluno, onde o dialogo seja por igual ou ainda colocar o outro no centro da discussão.

Ao finalizar aplicação da Sequência Didática, observa-se que alunos fazem contribuições, reforçando aspectos importantes que antes desconheciam e agora ao compreender esses aspectos importantes que precisam apenas atitudes simples, mostrando a importância da Educação Ambiental e fortalecendo essa ação para o Ensino de Ciências. Observou-se no discurso dos alunos que os conceitos utilizados foram construídos durante a Sequência Didática, pode-se perceber a evolução na mudança de atitudes, percebeu-se ainda o interesse para continuar com o processo de sensibilização com a comunidade escolar no que tange a questão do desperdício, descarte do lixo e deposição do mesmo considerando ser de interesse para melhoria da qualidade de vida de todos.

As rodas de conversa e sua idiossincrasia conduziram a pesquisa durante a Sequência Didática e tornaram possível a compreensão de dados que, talvez, não viessem à tona se não fossem despertados pelo interesse no diálogo e na partilha. Assim, a roda de conversa se firma como um instrumento de produção de dados da pesquisa narrativa, em que é possível haver uma ressonância coletiva, na medida em que se criam espaços de diálogo e de reflexão. 
Nesta perspectiva, considera-se extremamente valoroso apresentar aos alunos a temática do lixo como uma forma de tratamento e diminuição dos resíduos sólidos/ lixos produzidos na escola, em suas casas, bem como por outros espaços, entendendo-a como mudança viável de atitude a diminuição do mesmo.

Zabala (1998, p. 212) pondera a este respeito dizendo que: A função da escola e da verdadeira responsabilidade profissional passa por conseguir que nossos alunos atinjam o maior grau de competência em todas as suas capacidades, investindo todos os esforços em superar as deficiências que muitos deles carregam por motivos sociais, culturais e pessoais.

\section{Considerações Finais}

O presente trabalho surgiu de inquietações, questionamentos e reflexões acerca da Educação Ambiental como tema transversal no ensino que muitas vezes está ausente nas discussões da organização escolar ficando implícito e raramente explícito no processo formativo dos estudantes.

O desenvolvimento da Sequência Didática em Educação Ambiental amplia o conhecimento num contexto amplo e não reducionista, tratando a EA de forma integrada. Às vezes, a Educação Ambiental é episódica nas atividades didático-pedagógicas. É preciso considerar que "apesar de ser um tema importante e que permite o desenvolvimento de várias práticas, deve-se tomar cuidado para não tratá-lo de forma asséptica e fragmentada, que, como todo saber tratado dessa maneira, cristaliza-se" (BARIZAN; DAIBEM; RUIZ, 2003, p. 09).

A maioria dos professores não está preparada para inserir-se em discussões concernentes às questões ambientais. As deficiências que se verificam no contexto educacional e no ensino de Ciências quando se trabalha a Educação Ambiental se justificam, muitas vezes, por não haver clareza do que seja Meio ambiente e EA. Dessa forma, cumpre-nos delinear nossa discussão em torno das questões que dizem respeito à construção de conceitos relevantes para uma EA efetiva. A questão ambiental impõe à sociedade a busca de novas formas de pensar e agir para suprir as necessidades e garantir a sustentabilidade. 
O desenvolvimento da Sequência Didática para Educação Ambiental no Ensino de Ciências observada e avaliada recaiu sobre o Ensino Fundamental, pois se faz necessário iniciar o processo de Alfabetização Científica desde as primeiras séries permitindo que os aprendizes trabalhem ativamente no processo de construção dos conhecimentos que afligem sua realidade. É relevante que no currículo escolar seja proposto a inserção de Sequências Didáticas nas quais os educandos sejam levados à investigação científica em busca da resolução de problemas (REIGOSA-CASTRO e JIMÉNEZALEIXANDRE, 2000). Assim sendo, emerge um Ensino de Ciências capaz de fornecer aos discentes não somente conceitos científicos, mas que permite que os alunos possam "fazer ciência", sendo defrontados com problemas autênticos e que a investigação seja condição para a resolução dos mesmos. Assim é possível oportunizar que os alunos tenham entendimento da Ciência; que sejam capazes de compreender os temas científicos e tecnológicos e como estes se correlacionam com a sociedade e o ambiente e assim sejam capazes de discutir e refletir sobre os impactos potenciais e, como resultado, posicionarem-se criticamente frente aos temas socioambientais.

Conclui-se com o desenvolvimento do REA como produto educacional buscou suprir esta carência com base na temática da Pegada Ecológica do Lixo de forma sistematizada e contextualizada para sua inserção no currículo escolar. Devido ao fato da grande importância com que os temas ambientais têm sido tratados nos dias atuais, inclusive pela mídia, que tem procurado com frequência mostrar problemas ambientais e suas consequências, espero com esse trabalho contribuir com o professor a levar para a sala de aula essa mesma preocupação, porém com melhor fundamentação, visando à criação de uma sensibilização, consciência ambiental em seus estudantes. Pode-se afirmar que foi importante a elaboração de um Recurso Educacional contendo sugestões de trabalho a partir de temas ambientais que pode ser tratado em todos os níveis de ensino com atividades mais motivadoras e dinâmicas, tanto para o aluno quanto para o professor.

\section{Referências}

AMIEL, T. Educação aberta: configurando ambientes, práticas e recursos educacionais. In: SANTANA, B.; ROSSINI, C.; PRETTO, N. L.(orgs.). Recursos educacionais 
abertos: práticas colaborativas políticas públicas. Salvador: Edufba; São Paulo: Casa da Cultura Digital, p. 17-33, 2012.

BARIZAN, A. C. C.; DAIBEM, A. M. L. \& RUIZ, S. S. As representações sociais de meio ambiente e de Educação Ambiental e as potenciais práticas pedagógicas de alunos do curso de licenciatura em Ciências Biológicas da UNESP de Bauru (SP). In: Anais do II EPEA:abordagens epistemológicas e metodológicas. UFSCar /São Carlos/SP, p.1-14, 2003.

BRANDÃO, C. R. A pesquisa participante e a participação da pesquisa: Um olhar entre tempos e espaços a partir da América Latina. BRANDÃO, C. R.; STRECK, D. R. Pesquisa participante: o saber da partilha. Aparecida: Ideias \& Letras, p. 21-54. 2006.

BRASIL. Lei 9.795 de 27 de Abril de 1999. Disponível em: < http://www.planalto.gov.br/ccivil_03/Leis/L9795.htm > Acesso em: 02/04/2018.

CRESWELL, J. W. Projeto de pesquisa: método qualitativo, quantitativo e misto. Porto Alegre: Artmed, 2010.

DELIZOICOV, D; ANGOTTI, J. A.; PERnAMBUCO, M. M. Ensino de Ciências: Fundamentos e Métodos. $4^{a}$ edição. São Paulo: Cortez, 2011.

LEFF, H. Saber Ambiental: Sustentabilidade, Racionalidade, Complexidade, Poder. Petrópolis: Vozes, 2005.

MARQUES, R. Pegada ecológica do lixo: desenvolvimento crítico, analítico e científico na educação ambiental de estudantes do $6^{\circ}$ ano do ensino fundamental. 2018. 146 f. Dissertação (Mestrado em Formação Científica, Educacional e Tecnológica) Universidade Tecnológica Federal do Paraná, Curitiba, 2018. Disponível em: http://repositorio.utfpr.edu.br/jspui/handle/1/2964 > Acesso 03/05/2018.

MARQUES, R. ; BELlini, E. M. ; GONZALEZ, C. E. F. ; XAVIER, C. R. . Compostagem como ferramenta de aprendizagem para promover a Educação Ambiental no ensino de ciências. In: $8^{\circ}$ FIRS - Fórum Internacional de Resíduos Sólidos, 2017, Curitiba - PR. Anais do $8^{\circ}$ Fórum Internacional de Resíduos Sólidos. Porto Alegre - RS: Instituto Venturi para Estudos Ambientais, p. 01-10. 2017.

PPGFCET. FORMAÇÃO CIENTÍFICA, EDUCACIONAL E TECNOLÓGICA. Disponível em: <http://www.utfpr.edu.br/curitiba/estruturauniversitaria/diretorias/dirppg/programas/pp gfcet/conheca-o-fcet>. Acesso em: 03/05/2018.

PRETTO, N. L. Professores-autores em rede. In: SANTANA, B.; ROSSINI, C.; PRETTO, N(orgs.). Recursos educacionais abertos: práticas colaborativas políticas públicas. Salvador: Edufba; São Paulo: Casa da Cultura Digital, p. 91-108. 2012.

REIGOSA CASTRO, C. e JIMÉNEZ-ALEIXANDRE, M.P., "La Cultura Científica en la Resolución de Problemas en el Laboratorio", Enseñanza de las Ciencias, v.18, n.2, 275-284, 2000. 
ROSSINI, C.; GONZALEZ. C., REA: o debate em política pública e as oportunidades para o mercado. In: SANTANA, B.; ROSSINI, C.; PRETTO, N. L (orgs.). Recursos educacionais abertos: práticas colaborativas políticas públicas. Salvador: Edufba; São Paulo: Casa da Cultura Digital, p. 35-70, 2012.

SANTOS, H.M.N.; FEHR, M. Educação ambiental por meio da compostagem de resíduos sólidos orgânicos em escolas públicas de Araguari-MG. Caminhos de Geografia, Uberlândia v.8, n.24, p.163 - 183. 2007.

SILVA, R.N.M. da. Percepção Ambiental do Rio Itapecuru, nas cidades de Pirapemas, Cantanhêde, Itapecuru Mirim, Bacabeira, Santa Rita e Rosário. In: Congresso Brasileiro De Engenharia Sanitária E Ambiental, p.23, 2005.

SOUTO, A.C.G.; FELICIANO, A.L.P.; MARQUEZIN, C. Percepção ambiental: o problema do lixo na comunidade do Tururu, entorno da Mata do Janga, Paulista/PE. In: IX Jornada de Ensino, Pesquisa e Extensão - JEPEX 2009. UFRPE. Recife. 2009.

SOUZA, G.S. Horta escolar: um laboratório vivo de química. 2007. Disponível em: <http://www.webartigos.com/artigos/educacao-ambiental-horta-escolar-umlaboratorio-vivo-noensino-de-quimica/57249/>. Acesso em: 05/05/2018.

STAROBINAS, L., REA na educação básica: a colaboração como estratégia de enriquecimento dos processos de ensino In: SANTANA, B.; ROSSINI, C.; PRETTO, N. L. (orgs.). Recursos educacionais abertos: práticas colaborativas políticas públicas. Salvador: Edufba; São Paulo: Casa da Cultura Digital, p. 121-132. 2012.

UNESCO. Representação da UNESCO no Brasil. Recursos Educacionais Abertos (REA). Brasília, 2011. Disponível em: $>$ http://www.unesco.org/new/fileadmin/MULTIMEDIA/HQ/CI/WPFD2009/Portuguese _Decla ration.html > Acesso em: 02/06/2018.

ZABALA, A. A prática educativa: como ensinar. Porto Alegre: Artmed, 1998. 